\title{
The Influence of New Hydrophobic Silica Nanoparticles on the Surface Properties of the Films Obtained from Bilayer Hybrids
}

\author{
Cristian Petcu, Violeta Purcar *, Cătălin-Ilie Spătaru, Elvira Alexandrescu, Raluca Şomoghi, \\ Bogdan Trică, Sabina Georgiana Niţu, Denis Mihaela Panaitescu, Dan Donescu and \\ Maria-Luiza Jecu \\ R \& D National Institute for Chemistry and Petrochemistry-ICECHIM, Polymers Department, \\ Spl. Independentei 202,6th District, 060021 Bucharest, Romania; cpetcu@icf.ro (C.P.); \\ spataru.catalin@gmail.com (C.-I.S.); elviraalexandrescu@yahoo.com (E.A.); r.somoghi@gmail.com (R.S.); \\ trica.bogdan@gmail.com (B.T.); sabina.nitu@yahoo.com (S.G.N.); panaitescu@icf.ro (D.M.P.); \\ ddonescu@chimfiz.icf.ro (D.D.); jecu.luiza@icechim.ro (M.-L.J.) \\ * Correspondence: violetapurcar@yahoo.com; Tel.: +40-21-316-3093
}

Academic Editors: Xianghui Hou and Fang Xu

Received: 3 November 2016; Accepted: 16 February 2017; Published: 20 February 2017

\begin{abstract}
Ultra-hydrophobic bilayer coatings on a glass surface were fabricated by sol-gel process using hexadecyltrimethoxysilane $\left(\mathrm{C}_{16} \mathrm{TMS}\right)$ and tetramethoxysilane (TMOS) (1:4 molar ratio) as precursors. After coating, silica nanoparticles $\left(\mathrm{SiO}_{2} \mathrm{NPs}\right)$ functionalized with different mono-alkoxy derivatives (methoxytrimethylsilane, TMeMS; ethoxydimethylvinylsilane, DMeVES; ethoxydimethylphenylsilane, $\mathrm{DMePhES}$; and methoxydimethyloctylsilane, $\mathrm{DMeC}_{8} \mathrm{MS}$ ) were added, assuring the microscale roughness on the glass surface. Influences of the functionalized $\mathrm{SiO}_{2} \mathrm{NPs}$ and surface morphology on the hydrophobicity of the hybrid films were discussed. The successful functionalization of $\mathrm{SiO}_{2} \mathrm{NPs}$ with hydrophobic alkyl groups were confirmed by Fourier transform infrared spectroscopy (FTIR). The thermal stability of hydrophobic $\mathrm{SiO}_{2} \mathrm{NPs}$ showed that the degradation of the alkyl groups takes place in the $200-400{ }^{\circ} \mathrm{C}$ range. Bilayer coating with $\mathrm{C}_{16} \mathrm{TMS} / \mathrm{TMOS}$ and $\mathrm{SiO}_{2}$ NPs modified with alkoxysilane substituted with $\mathrm{C}_{8}$ alkyl chain $\left(\mathrm{SiO}_{2}\right.$ $\mathrm{NP}-\mathrm{C}_{8}$ ) has micro/nano structure. Hydrophobicity of functionalized $\mathrm{SiO}_{2} \mathrm{NPs}-\mathrm{C}_{8}$ and its higher degree of nanometer-scale roughness gave rise to ultra-hydrophobicity performance for bilayer coating $\mathrm{C}_{16} \mathrm{TMS} / \mathrm{TMOS}+\mathrm{SiO}_{2} \mathrm{NPs} \mathrm{C}_{8}\left(145^{\circ}\right)$, compared to other similar hybrid structures. Our synthesis method for the functionalization of $\mathrm{SiO}_{2} \mathrm{NPs}$ is useful for the modification of surface polarity and roughness.
\end{abstract}

Keywords: sol-gel process; silica nanoparticles; nanostructuration; organic-inorganic hybrids; trialkylmonoalkoxysilanes

\section{Introduction}

To obtain highly hydrophobic surfaces, a large number of review-type studies have been designed. The main properties of highly hydrophobic surfaces are weak water adhesion and self-cleaning behavior in the presence of wetting phenomenon. In most cases, these surfaces are used in construction, dyes, windshield and window manufacturing, headlights, automobiles, solar panels, good thermal transfer pipe-lines, sensors, etc. [1-4].

A large and diverse number of methods to obtain highly hydrophobic surfaces have been reported, such as multi-step chemical methods and physical methods that create roughness $[1,5,6]$. Various functional silane precursors-polymethylhydrosiloxane, poly(vinyl chloride), fluorinated 
methacrylate, and mercapto functional monomers were used in most situations of sol-gel method in order to fabricate superhydrophobic surfaces [7].

From analysis of the published data, two approaches for obtaining hydrophobic surfaces from particles and binder were notable: mixing the two phases [8-11], or deposition of particles over films obtained from different film-forming procedures [12-22]. In this way, the possibility of obtaining superhydrophobic surfaces (contact angle $>160^{\circ}$ ) by mixing silica nanoparticles $\left(\mathrm{SiO}_{2} \mathrm{NPs}\right.$ ) with a binder obtained from tetraethoxysilane (TEOS) and a fluorosilane (FAS) through acid-catalyzed sol-gel process were reported [8,9]. In the case of depositing $\mathrm{SiO}_{2} \mathrm{NPs}$ over different supports, ultrahydrophobic surfaces were obtained by functionalizing the fillers with hydrocarbon chains [12-15].

Thereby, functionalizing silica particles with trichlorosilanes led to the formation of surfaces whose hydrophobicity increase with increasing alkyl chain length. When n-octadecyltrichlorosilane (ODTS) was used for hydrophobic process, a contact angle (CA) of $162^{\circ}$ was achieved [12]. Xiu et al. [13] report the effect of surface hydrophobicity on the measured contact angles on the rough surfaces. It was demonstrated that superhydrophobic surfaces can be obtained using silica nanoparticles functionalized with silanes containing different hydrocarbon or fluorocarbon chains.

Yilgor et al. [14] synthesized $\mathrm{SiO}_{2} \mathrm{NP}$ depositions with controllable hydrophobicity using mixtures of hydrophilic silica with hydrophobic silica (modified with trimethylchlorosilanes) onto the polymer surface. Another research group obtained superhydrophobic films using $\mathrm{SiO}_{2}$ nanoparticles (synthesized with TEOS in emulsions containing toluene and a mixture of neutral and anionic surfactants) deposited on glass substrates [15]. Superhydrophobic silica layers obtained by thermally treating a mixture that contained dual-sized polystyrene particles were reported [16]. The final process of hydrophobization was accomplished in dodecafluoroheptyl-methyldimethoxysilane vapors, showing excellent superhydrophobic property of silica film. Additionally, a covalent bond between the two phases can represent a special way of ensuring the deposition of silica particles over a polymer matrix [17-20]. "Layer-by-layer" (LBL) gradual deposition of dual-sized silica particles on glass functionalized with $\mathrm{NH}_{3}{ }^{+}$groups and modified with dodecyltrichlorosilane was shown in [21]. Similar CA values were obtained for LBL depositions [22] of $\mathrm{SiO}_{2} \mathrm{NP}$ dispersions over polymer layers with polyalkylamine hydrochloride.

This paper will focus on the aspect of synthesis, size-dependent properties, and modification of silica nanoparticles $\left(\mathrm{SiO}_{2} \mathrm{NPs}\right.$ ) by sol-gel method using different alkoxysilanes (substituted with dimethyl and methyl, vinyl, phenyl, or octyl alkyl group) toward the preparation of bilayer coatings on a glass surface. The influence of the functionalized $\mathrm{SiO}_{2} \mathrm{NPs}$ with mono-alkoxy derivatives (methoxytrimethylsilane, TMeMS; ethoxydimethylvinylsilane, DMeVES; ethoxydimethylphenylsilane, DMePhES; methoxydimethyloctylsilane, $\mathrm{DMeC}_{8} \mathrm{MS}$ ) on the hydrophobicity is studied. The comparative analysis brings new information regarding the interactions between the alkyl group from the functionalized $\mathrm{SiO}_{2} \mathrm{NPs}$ layer and hexadecyltrimethoxysilane $\left(\mathrm{C}_{16} \mathrm{TMS}\right)$ / tetramethoxysilane (TMOS) hybrid film. Our synthesis method is useful for the modification of surface polarity and wettability. The resultant coatings are characterized through various techniques, including dynamic light scattering (DLS), Fourier transform infrared spectroscopy (FTIR), thermogravimetric analysis (TGA), environmental scanning electron microscopy (ESEM), transmission electron microscopy (TEM), atomic force microscopy (AFM), and water contact angles (CA).

\section{Results and Discussion}

For increasing hydrophobicity, it is well known that the only method which does not involve any additional oligomerization reactions is the use of monochloro- or monoalkoxysilanes $[4,5,23]$. In the case of functionalizing silica particles or dispersed layered silicates, silanes with two or three reactive groups can induce aggregation of the fillers due to the formation of multiple covalent bonds [24,25]. The only difficulty when the functionalization is performed with monofunctional silanes is weak reactivity $[23,26]$. In order to increase the reactivity, in this study, ultrasonication was used throughout the entire reaction and heating process [27]. 
The functionalization reaction was confirmed by measuring the average diameters of the silica particles dispersed in ethanol (Figure 1a) and methylene chloride (Figure 1b). The highest value was obtained for the silica functionalized with long alkyl chain (sample 5, Figure 1b). These results agree with previous results regarding mesoporous organized silica functionalization. When the auxiliary organic species are added to the reaction gel, they are solubilized inside the hydrophobic regions of material, causing an increase in the pore size of the final product [28]. Experiments have shown that the $\mathrm{SiO}_{2}$ NPs functionalized with short alkyl groups in the reaction mixture lead to a smaller particle size compared to pristine $\mathrm{SiO}_{2} \mathrm{NPs}$ only as a source of silica. These findings indicate that the addition of organosilane with short alkyl group affect the nucleation process and lead to a larger number of formed nuclei. Thus, smaller particle size is obtained (samples $2-4$ ). The average particle size increased for sample 5 (see Figure 1b), and this effect can be caused by steric hindrance and is seen notably in branched chain (longer alkyl chain leads to lower hydrolysis rate). The stability of the particle dispersion can be achieved by steric stabilization, and is almost attained by proper particle surface functionalization.
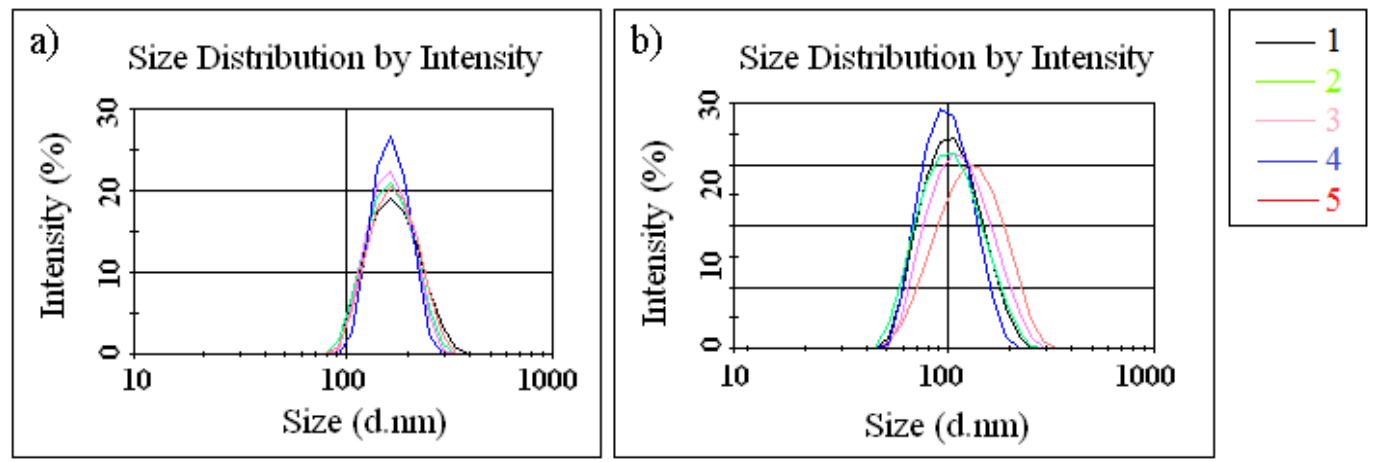

Figure 1. The average particle size of pristine silica nanoparticles $\left(\mathrm{SiO}_{2} \mathrm{NPs}\right)$ and functional $\mathrm{SiO}_{2} \mathrm{NPs}$ dispersed in: (a) ethanol and (b) methylene chloride.

The existence of alkyl groups on the silica surface is confirmed by FTIR spectra (Figure 2), in agreement with previously published data [12,27]. For all samples, the Si-O-Si symmetric and asymmetric bands located at $\sim 800 \mathrm{~cm}^{-1}$ and $\sim 1100 \mathrm{~cm}^{-1}$, respectively, and the band at $950 \mathrm{~cm}^{-1}$ corresponding to the Si-O group can be observed [29-31]. The intensity of the C-H stretching bands (peaks observed at $2923 \mathrm{~cm}^{-1}$ and $2863 \mathrm{~cm}^{-1}$, respectively) is highest for the silica modified with longest alkyl chains $\left(\mathrm{C}_{8}\right)$ (sample 5). Substitution with a shorter alkyl chain is characterized by a change in the absorption maximum and a reduced intensity of the bands. This phenomenon can occur due to a different conformation of the alkyl chains [30] and a lower concentration [12] (samples 2-4). In the case of methyl group substitution (sample 1), no significant absorption can be observed in the mentioned wavelength domain.

Chemical modifications with monoalkoxysilanes after the reaction were outlined by the thermal degradation of the new reaction products. In Table 1, the TGA data are given for the three temperature steps. From previously published studies [12,27], the weight loss in the $25-200{ }^{\circ} \mathrm{C}$ interval corresponds to the vaporization of the solvent adsorbed on the particles [32,33]. The thermo-oxidative degradation of the alkyl groups caused by a hydrophobic process takes place in the $200-400{ }^{\circ} \mathrm{C}$ range. The last degradation step-from 400 to $700{ }^{\circ} \mathrm{C}$ - corresponds to the condensation reaction of the $\mathrm{OH}$ groups from the partially modified silica surfaces [34]. 


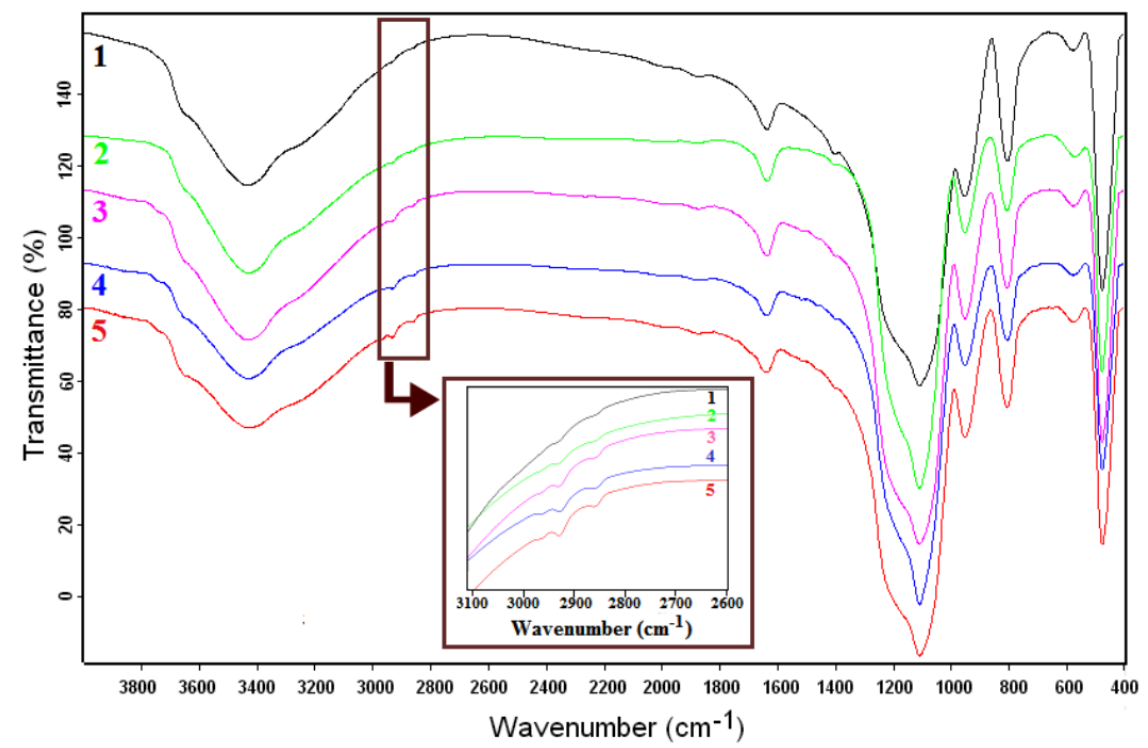

Figure 2. Fourier transform infrared (FTIR) spectra of dried $\mathrm{SiO}_{2} \mathrm{NPs}$.

Table 1. Thermal degradation of dried $\mathrm{SiO}_{2} \mathrm{NPs}$.

\begin{tabular}{ccccc}
\hline \multirow{2}{*}{ Sample No. } & \multicolumn{4}{c}{$\Delta \mathrm{G}(\boldsymbol{\%}$ grav. $) / \mathrm{T}_{\max }\left({ }^{\circ} \mathbf{C}\right)$} \\
\cline { 2 - 5 } & $\mathbf{2 5 - 2 0 0}{ }^{\circ} \mathbf{C}$ & $\mathbf{2 0 0 - 4 0 0}{ }^{\circ} \mathbf{C}$ & $\mathbf{4 0 0 - 7 0 0}{ }^{\circ} \mathbf{C}$ & Residue (\%) \\
\hline 1 & $7.0 / 47.3$ & $2.2 / 277.4$ & $2.5 / 461.0$ & 88.3 \\
2 & $6.5 / 48.6$ & $2.8 / 263.0$ & $2.4 / 451.0$ & 88.3 \\
3 & $6.4 / 48.2$ & $2.8 / 272.0$ & $2.5 / 462.1$ & 88.3 \\
4 & $6.3 / 51.4$ & $2.8 / 293.0$ & $2.7 / 453.0$ & 88.2 \\
5 & $6.3 / 50.4$ & $3.1 / 257.8$ & $2.5 / 435.0$ & 88.2 \\
\hline
\end{tabular}

The morphology and size of the obtained particles have been examined by environmental scanning electron microscopy and transmission electron microscopy. ESEM and TEM analyses (Figures 3 and 4) were performed to confirm the DLS measurements. For this purpose, dried pristine $\mathrm{SiO}_{2} \mathrm{NP}$ (sample 1) and dried $\mathrm{SiO}_{2} \mathrm{NP}$ modified with $\mathrm{C}_{8}$ (sample 5) dispersed in ethanol were analyzed. For sample 1, it can be observed that not all particles are spherical, and some of them are irregular. $\mathrm{SiO}_{2} \mathrm{NPs}_{\text {with a size }}$ range of 140-170 nm were obtained. Synthesized silica nanoparticles functionalized with long alkyl chain are spherical in shape with diameter of $150 \mathrm{~nm}$ (sample 5).
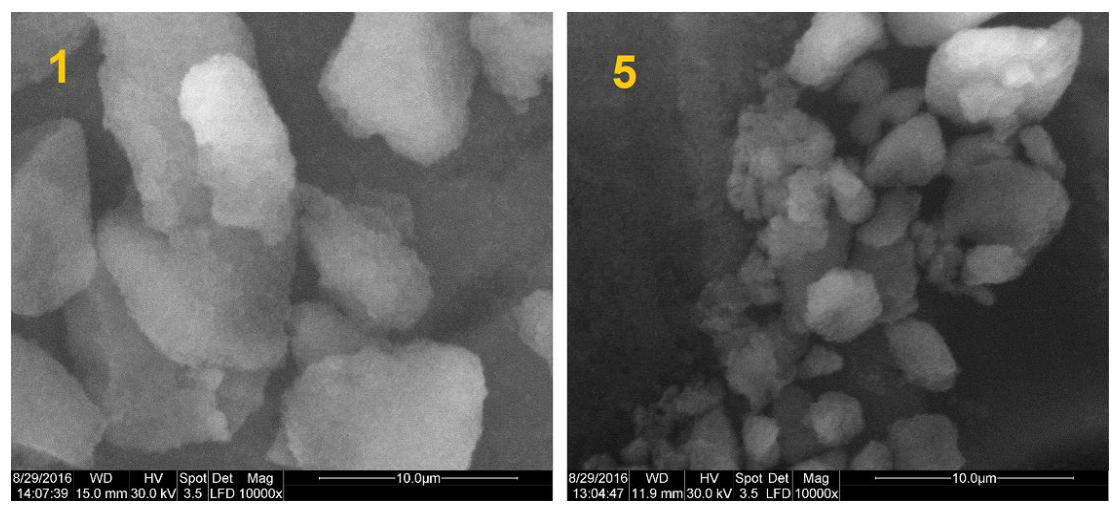

Figure 3. Environmental scanning electron microscopy (ESEM) images of dried pristine $\mathrm{SiO}_{2} \mathrm{NPs}$ (sample 1) and dried $\mathrm{SiO}_{2} \mathrm{NPs}$ modified with long alkyl chain (sample 5), dispersed in ethanol. 

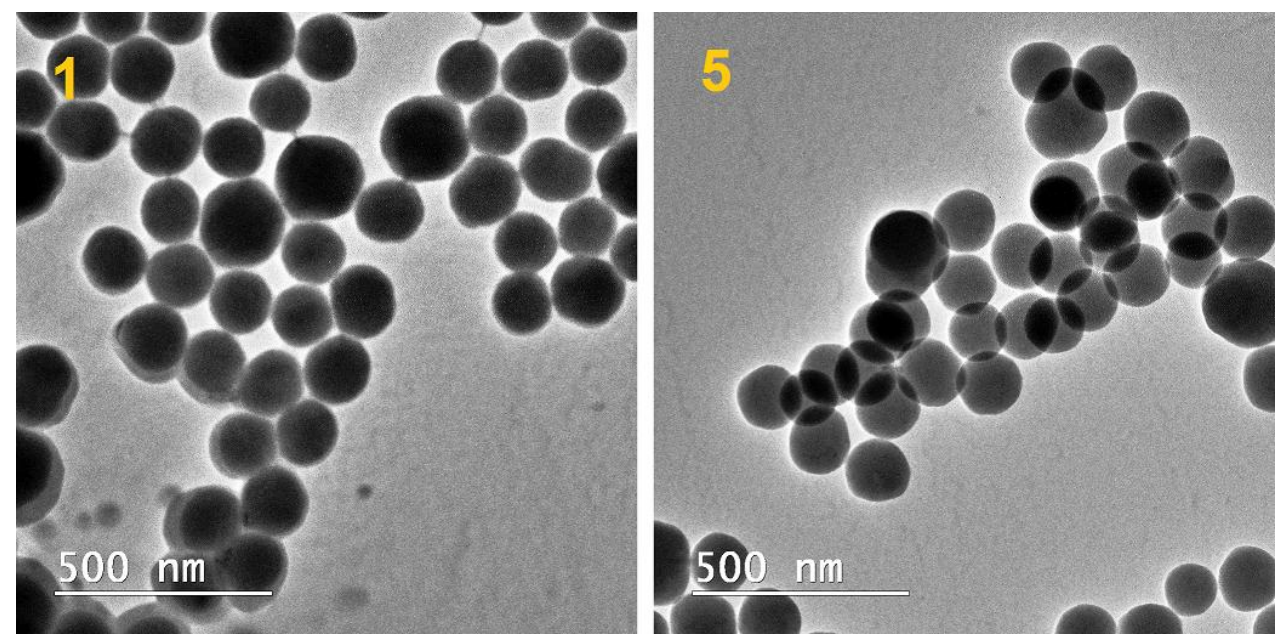

Figure 4. TEM images of dried pristine $\mathrm{SiO}_{2} \mathrm{NPs}$ (sample 1) and dried $\mathrm{SiO}_{2} \mathrm{NPs}_{\text {modified with long }}$ alkyl chain (sample 5), dispersed in ethanol.

The wetting ability and surface roughness changes of the bilayer coatings were evaluated by contact angle (CA) measurement and AFM topography, respectively, and the results are as shown in Figures 5 and 6. Figure 5 shows the contact angle (CA) of a $5 \mu \mathrm{L}$ water droplet on the bilayer coatings. Comparing the $C A$ values, a maximum value $\left(145^{\circ}\right)$ was obtained for bilayer coating with $\mathrm{C}_{16} \mathrm{TMS} / \mathrm{TMOS}$ and $0.01 \mathrm{~g}$ of $\mathrm{SiO}_{2} \mathrm{NPs}$ functionalized with $\mathrm{DMeC}_{8} \mathrm{MS}$ dispersed in $1 \mathrm{~mL} \mathrm{EtOH}$ (coating $C_{5}$ ). This observation means that the coated surface is rough on the micro/nanometer scale. For coatings $C_{1}-C_{4}$, the degree of roughness was not sufficient, and ultra-hydrophobicity was not achieved. This effect can be explained by considering the chemical reactivity of functionalized silica nanoparticles that were not strongly fixed to the first layer $\left(\mathrm{C}_{16} \mathrm{TMS} / \mathrm{TMOS}\right)$. The surface hydrophobicity is in fact due to the presence of functional hydrophobic groups that start to adhere to the base silicate matrix.

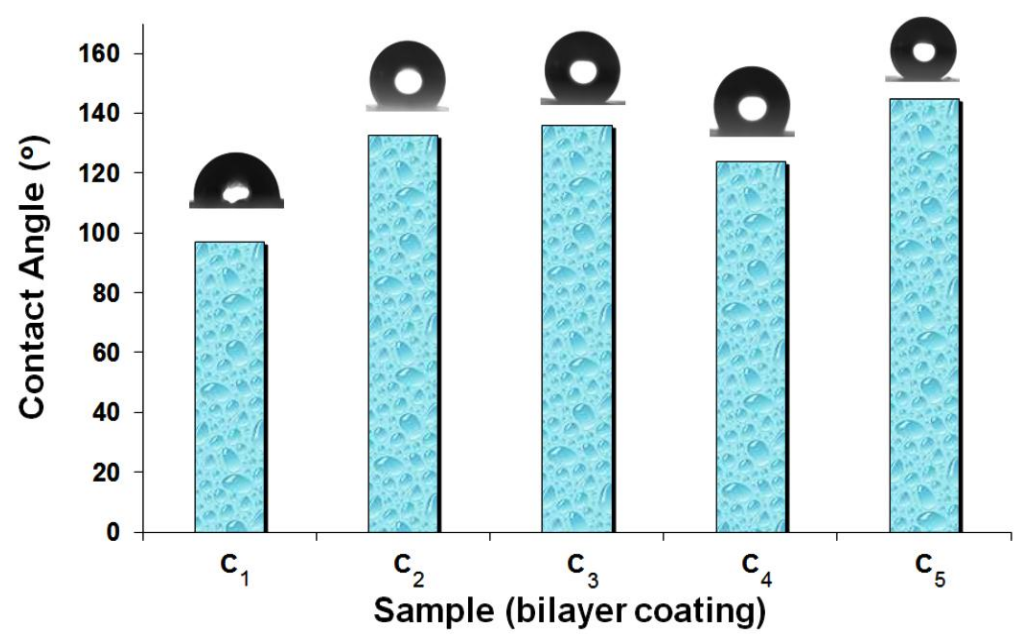

Figure 5. Contact angle of the bilayer coatings (see Table 3).

Figure 6 shows AFM topographic images of $\mathrm{C}_{16} \mathrm{TMS} / \mathrm{TMOS}$ monolayer hybrid film (coating $C_{0}$ ), and of bilayer coating $\left(\mathrm{C}_{16} \mathrm{TMS} / \mathrm{TMOS}+0.01 \mathrm{~g}\right.$ of $\mathrm{SiO}_{2} \mathrm{NPs}$ functionalized with $\mathrm{DMeC}_{8} \mathrm{MS}$ dispersed in $1 \mathrm{~mL}$ EtOH, coating $C_{5}$ ). As can be observed, the starting $\mathrm{C}_{16} \mathrm{TMS} / \mathrm{TMOS}$ hybrid film surface is quite smooth. Sample 5 presents a rough surface, which is attributed to the adhesion between functionalized $\mathrm{SiO}_{2}$ NPs with long alkyl group and $\mathrm{Si}-\mathrm{O}$ - groups from the $\mathrm{C}_{16} \mathrm{TMS} / \mathrm{TMOS}$ substrate. The higher degree of nanometer-scale roughness gave rise to ultra-hydrophobicity. 


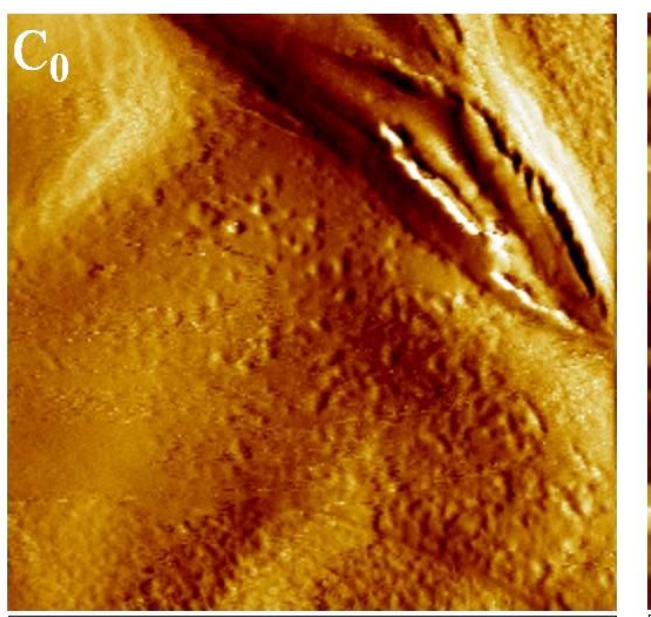

0.0

$2.0 \mu \mathrm{m}$

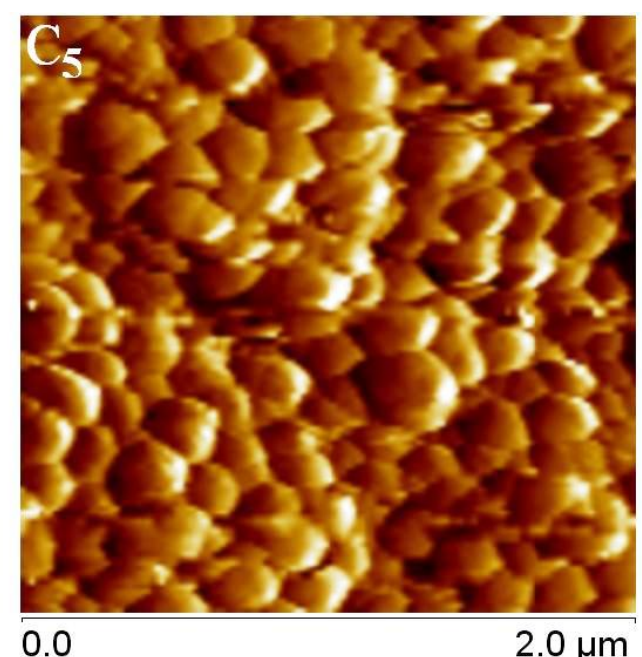

Figure 6. Atomic force microscopy (AFM) topographic images of structured coatings: monolayer hybrid hexadecyltrimethoxysilane/ tetramethoxysilane ( $\mathrm{C}_{16} \mathrm{TMS} / \mathrm{TMOS}$ ) film (coating $\mathrm{C}_{0}$ ), and bilayer coating $\left(\mathrm{C}_{16} \mathrm{TMS} / \mathrm{TMOS}+0.01 \mathrm{~g}\right.$ of $\mathrm{SiO}_{2} \mathrm{NPs}$ functionalized with methoxydimethyloctylsilane ( $\left.\mathrm{DMeC}_{8} \mathrm{MS}\right)$ dispersed in $1 \mathrm{~mL} \mathrm{EtOH}$, coating $\mathrm{C}_{5}$ ).

\section{Experimental Section}

\subsection{Materials}

Tetraethylorthosilicate (TEOS, 98\%, Aldrich, Steinheim, Germany), methoxytrimethylsilane (TMeMS, 97\%, Fluka, Steinheim, Germany), ethoxydimethylvinylsilane (DMeVES, 97\%, Alfa Aesar, Swedesboro, NJ, USA), ethoxydimethylphenylsilane (DMePhES, 97\%, Fluka, Steinheim, Germany), methoxydimethyloctylsilane (DMeC 8 MS, 98\%, Aldrich, Steinheim, Germany), methoxydimethyloctadecylsilane ( $\mathrm{DMeC}_{18} \mathrm{MS}, 90 \%$, Aldrich, Steinheim, Germany), hexadecyltrimethoxysilane ( $\mathrm{C}_{16} \mathrm{TMS}, 85 \%$, Aldrich, Steinheim, Germany), ethanol (reagent grade, CHIMREACTIV SRL), ammonia (reagent grade, $32 \mathrm{wt}$ \%, Scharlau, Sentmenat, Spain), hydrochloric acid (reagent grade, 37 wt. \%, Riedel, Seelze, Germany), toluene (reagent grade, CHIMREACTIV SRL).

\subsection{Preparation of Silica Nanoparticles $\left(\mathrm{SiO}_{2} \mathrm{NPS}\right)$}

The synthesis of hydrophobic modified $\mathrm{SiO}_{2}$ nanoparticles $\left(\mathrm{SiO}_{2} \mathrm{NPs}\right)$ was realized in two steps by a method adapted from a study published by Kulkarni et al. [11].

\subsubsection{Synthesis of the Pristine Silica Nanoparticles}

TEOS $(32.5 \mathrm{~g})$ and $125 \mathrm{~mL}$ absolute ethanol $(\mathrm{EtOH})$ were initially introduced in a three-neck round-bottom flask with a mechanical stirrer (400 rot/ $\mathrm{min}$ ) and a reflux condenser. Under stirring, a mixture of $75 \mathrm{~mL} \mathrm{NH} \mathrm{NH}_{4} \mathrm{OH}(25 \%)$ and $570 \mathrm{~mL}$ absolute $\mathrm{EtOH}$ was added for $2 \mathrm{~h}$. After addition of $\sim 100 \mathrm{~mL}$ of ammonia solution, the mixture turned opalescent. At the end of the addition of the ammonia solution, the mixture was kept under stirring for another two hours. The mixture was put in Petri dishes, and the volatile compounds were allowed to evaporate at ambient temperature and in vacuum at $60{ }^{\circ} \mathrm{C}$. After drying, $9.33 \mathrm{~g} \mathrm{SiO}_{2} \mathrm{NPs}$ were obtained (sample 1) and used for their functionalization with various mono-alkoxy derivatives.

\subsubsection{Functionalization of the Silica Nanoparticles with Various Mono-Alkoxy Derivatives}

Different alkoxysilanes: methoxytrimethylsilane (TMeMS), ethoxydimethylvinyl silane (DMeVES), ethoxydimethylphenylsilane (DMePhES), and methoxydimethyloctylsilane ( $\mathrm{DMeC}_{8} \mathrm{MS}$ ) were used to functionalize the $\mathrm{SiO}_{2} \mathrm{NPs}$ by sol-gel process. $\mathrm{SiO}_{2}(1.5 \mathrm{~g}$, synthesized in Section 3.2.1) 
and $100 \mathrm{~mL}$ of toluene (dried on molecular sieves and deoxygenated with nitrogen) were added in a three-neck round-bottom flask provided with mechanical stirrer and reflux condenser. The entire mixture was heated at $50{ }^{\circ} \mathrm{C}$ under continuous stirring. Then, 7.5 mmoles of mono-alkoxy derivatives substituted with dimethyl and methyl, vinyl, phenyl, octyl, and octadecyl were added to the heated mixture. The mixture was kept at $50{ }^{\circ} \mathrm{C}$ under ultrasonication (in an ultrasonic bath) for $4 \mathrm{~h}$. Subsequently, the mixture was dried in air at room temperature (samples 2-5) (see Table 2). The resulting functionalized silica particles and corresponding coatings are described in Table 3.

Table 2. Synthesis conditions for functionalization of silica.

\begin{tabular}{ccc}
\hline \multirow{2}{*}{ Sample No. } & \multicolumn{2}{c}{ Synthesis } \\
\cline { 2 - 3 } & Pristine $\mathbf{S i O}_{\mathbf{2}}$ Particles $\mathbf{( g )}$ & $\mathbf{R}\left(\mathrm{CH}_{3}\right)_{2} \mathrm{SiOR}^{\prime}$ * \\
\hline 1 & 1.5 & 0 \\
2 & 1.5 & $\mathrm{Me}_{3} \mathrm{SiOMe}$ \\
3 & 1.5 & $\mathrm{VMe}_{2} \mathrm{SiOEt}$ \\
4 & 1.5 & $\mathrm{PhMe}_{2} \mathrm{SiOEt}$ \\
5 & 1.5 & $\mathrm{C}_{8} \mathrm{Me}_{2} \mathrm{SiOMe}^{-}$ \\
\hline${ }^{*} \mathrm{R}=-\mathrm{CH}_{3}(\mathrm{Me}),-\mathrm{CH}_{2}=\mathrm{CH}_{2}-(\mathrm{V}), \mathrm{C}_{6} \mathrm{H}_{5}-(\mathrm{Ph}), \mathrm{CH}_{3}-\left(\mathrm{CH}_{2}\right)_{7}-\left(\mathrm{C}_{8}\right) ; \mathrm{R}^{\prime}=-\mathrm{CH}_{3}(\mathrm{Me}),-\mathrm{CH}_{2}-\mathrm{CH}_{3}(\mathrm{Et})$.
\end{tabular}

Table 3. Composition of functionalized silica particles and the corresponding coatings.

\begin{tabular}{ccc}
\hline Sample No. & Composition & Corresponding Coatings \\
\hline- & - & $\mathrm{C}_{0}$ \\
1 & Pristine $\mathrm{SiO}_{2} \mathrm{NP}$ & $\mathrm{C}_{1}$ \\
2 & $\mathrm{SiO}_{2} \mathrm{NP}$ functionalized with TMeMS & $\mathrm{C}_{2}$ \\
3 & $\mathrm{SiO}_{2} \mathrm{NP}$ functionalized with DMeVES & $\mathrm{C}_{3}$ \\
4 & $\mathrm{SiO}_{2} \mathrm{NP}$ functionalized with DMePhES & $\mathrm{C}_{4}$ \\
5 & $\mathrm{SiO}_{2} \mathrm{NP}$ functionalized with DMeC ${ }_{8} \mathrm{MS}$ & $\mathrm{C}_{5}$ \\
\hline
\end{tabular}

\subsection{Fabrication of the Bilayer Coatings on the Glass Substrate}

\subsubsection{Preparation of the First Coating Layer}

The glass substrates were firstly covered with acidic solution (prepared in a similar way to that previously reported [6]) containing hexadecyltrimethoxysilane $\left(\mathrm{C}_{16} \mathrm{TMS}\right)$ and tetramethoxysilane (TMOS). Then, $1.21 \mathrm{~g}$ of $\mathrm{C}_{16}$ TMS and the amount of TMOS required to obtain a molar ratio of $1 / 4$ were dissolved under continuous stirring in $8.04 \mathrm{~mL} \mathrm{EtOH}$ and then heated at $40{ }^{\circ} \mathrm{C}$. When the final temperature was achieved, $1.04 \mathrm{~mL}$ of $\mathrm{HCl}(0.1 \mathrm{~N}$ solution) was added. The solution was stirred for another $90 \mathrm{~min}$. The molar ratios used for the reaction mixture were as follows: $\mathrm{C}_{16}$ TMS:TMOS:EtOH: $\mathrm{H}_{2} \mathrm{O}: \mathrm{HCl}=1: 4: 50: 19: 0.03$. The obtained hybrid solution was deposited onto a glass slide by draw down sample coating with the manual applicator. The resultant first layer was left to dry at room temperature for $24 \mathrm{~h}$ (coating $C_{0}$ ).

\subsubsection{Preparation of the Second Coating Layer}

A second solution ( $0.01 \mathrm{~g}$ of dried functionalized $\mathrm{SiO}_{2}$ nanoparticles dispersed in $10 \mathrm{~mL} \mathrm{EtOH}$ and mixed for approximately $2 \mathrm{~h}$ ) was deposited over the first layer in order to obtain bilayer coatings (coatings $C_{1}-C_{5}$ ).

The resultant functionalized silica particles and corresponding coatings are described in Table 3.

\subsection{Characterization Methods}

The initial solutions were examined by dynamic light scattering (DLS) to measure the particle diameters (Zetasizer, Malvern Nano ZS). The solutions were diluted in ethanol and methylene chloride ( $0.1 \mathrm{~mL}$ sample dissolved in $25 \mathrm{~mL}$ solvent and ultrasonicated $5 \mathrm{~min}$.). 
FTIR spectra of dried samples were obtained using a Fourier transform infrared spectrophotometer (Tensor 37 from Bruker). The samples were ground with $\mathrm{KBr}$ and pressed to form a disc for FTIR scanning. For all scans, the spectra were collected over the wavenumber range of $400-4000 \mathrm{~cm}^{-1}$, with a resolution of $4 \mathrm{~cm}^{-1}$.

TGA analyses of dried functionalized $\mathrm{SiO}_{2} \mathrm{NPs}$ were performed in $\mathrm{N}_{2}\left(10{ }^{\circ} \mathrm{C} / \mathrm{min}\right), 25-700{ }^{\circ} \mathrm{C}$ range, using a TA TGA Q5000 IR instrument.

The morphology of silica particles was imaged using environmental scanning electron microscopy (ESEM) (FEI QUANTA 200) and by Transmission Electron Microscopy (TEM), employing a Tecnai ${ }^{\mathrm{TM}}$ G2 F20 TWIN Cryo-TEM instrument (FEI Company) at $200 \mathrm{kV}$ acceleration voltages. The ESEM images were obtained in the low-vacuum mode. The samples were deposited on a conductive stub and dried at room temperature. For TEM analysis, the samples were observed directly without further staining to improve contrast. A droplet of diluted sample was poured on a carbon film-coated copper grid and allowed to dry in air at room temperature.

Contact angles of bilayer coatings were determined using a CAM 200 Contact Angle Tensiometer instrument from KSV Instruments equipped with a digital camera that was connected to a PC. Water was used as the liquid for the contact angle measurements. The contact angles were calculated from the drop images after the shape accentuation, radius, and string reading were determined.

The roughness of bilayer coatings were studied using an atomic force microscope (AFM) from Bruker, Santa Barbara, equipped with a Nanoscope V controller and a MultiMode head. The equipment was operated in tapping mode using an etched silicon tip (nominal radius $8 \mathrm{~nm}$ ), a cantilever length of $225 \mu \mathrm{m}$, and a resonant frequency of approximately $75 \mathrm{kHz}$. AFM measurements were performed at room temperature with a scan rate of $1 \mathrm{~Hz}$ and a scan angle of $0^{\circ}$.

\section{Conclusions}

Bilayer coatings on glass surfaces were fabricated using functionalized silica nanoparticles obtained by sol-gel process (ultrasonication at $50{ }^{\circ} \mathrm{C}$ ). FTIR spectra confirmed the existence of the alkyl groups over the silica surface, in agreement with previously published data. The intensity of the $\mathrm{C}-\mathrm{H}$ stretching bands was the highest in the case of silica modified with long alkyl chain $\left(C_{8}\right)$. Substitution with a shorter alkyl chain was characterized by a modified absorption maximum and a reduced intensity of the bands; methyl group substitution proved to have no significant absorption that could be observed in the mentioned wavelength domain. The thermal stability of the dried silica nanoparticles showed that the weight loss occurred stepwise, and indicated that silica nanoparticles began to lose hydrophobicity when heated in the $200-400{ }^{\circ} \mathrm{C}$ range. ESEM and TEM analyses of samples dried and dispersed in ethanol showed that the silica nanoparticles are mostly spherical in shape, with diameter of $\sim 150 \mathrm{~nm}$. The AFM measurements showed that the starting $\mathrm{C}_{16} \mathrm{TMS} / \mathrm{TMOS}$ hybrid film surface has smooth surface. Bilayer coating with $\mathrm{SiO}_{2} \mathrm{NPs}$ modified with $\mathrm{C}_{8}$ chain present a higher degree of nanometer-scale roughness $\left(\mathrm{CA}=145^{\circ}\right)$. The obtained bilayer coatings can be useful and helpful to construct artificial anti-wetting surfaces for numerous practical applications.

Supplementary Materials: The following are available online at http://www.mdpi.com/2079-4991/7/2/47/s1, Table S1: DLS results for functionalized silica nanoparticles.

Acknowledgments: The work has been funded by the Program ERANET “Towards an ERA in Industrial Biotechnology" (ERA-IB), project number 62/2016 and by the grant funded by the Romanian National Authority for Scientific Research, project number PN16.31.03.04. 
Author Contributions: Violeta Purcar, Cristian Petcu, Dan Donescu, were involved in designing the aim of this manuscript, did the experiments and prepared the manuscript. Cătălin-Ilie Spătaru, Elvira Alexandrescu, Raluca Şomoghi, Bogdan Trică, Sabina Georgiana Niţu and Denis Mihaela Panaitescu performed the analyses. Maria-Luiza Jecu contributed as manuscript advisor. Each contributor was essential to the production of this work.

Conflicts of Interest: The authors declare no conflict of interest.

\section{References}

1. Roach, P.; Shirtcliffe, N.J.; Newton, M.I. Progress in Superhydrophobic Surface Development. Soft Matter 2008, 4, 224-240. [CrossRef]

2. Ma, M.; Hill, R.M. Superhydrophobic surfaces. Curr. Opin. Colloid Interface Sci. 2006, 11, 193-202. [CrossRef]

3. Feng, X.J.; Jiang, L. Design and creation of superwetting/antiwetting surfaces. Adv. Mater. 2006, 18, 3063-3078. [CrossRef]

4. Gao, L.; McCarthy, T.J. How Wenzel and Cassie Were Wrong. Langmuir 2007, 23, 3762-3765. [CrossRef] [PubMed]

5. Shimojima, A.; Kuroda, K. Designed synthesis of nanostructured siloxane-organic hybrids from amphiphilic silicon-based precursors. Chem. Rec. 2006, 6, 53-63. [CrossRef] [PubMed]

6. Spataru, C.I.; Purcar, V.; Ghiurea, M.; Radovici, C.; Stanga, G.; Donescu, D. Effects of the nanoassociation of hexadecyltrimethoxysilane precursors on the sol-gel process. J. Sol-Gel Sci. Technol. 2013, 65, 344-352. [CrossRef]

7. Nagappan, S.; Park, S.S.; Ha, C.S. Recent advances in superhydrophobic nanomaterials and nanoscale systems. J. Nanosci. Nanotechnol. 2014, 14, 1441-1462. [CrossRef] [PubMed]

8. Li, L.; Li, B.; Dong, J.; Zhang, J. Roles of silanes and silicones in forming superhydrophobic and superoleophobic materials. J. Mater. Chem. A 2016, 4, 13677-13725. [CrossRef]

9. Han, J.T.; Kim, S.Y.; Woo, J.S.; Lee, G.W. Transparent, conductive, and superhydrophobic films from stabilized carbon nanotube/silane sol mixture solution. Adv. Mater. 2008, 20, 3724-3727. [CrossRef]

10. Wu, Z.; Han, H.; Han, W.; Kim, B.; Ahn, K.H.; Lee, K. Controlling the hydrophobicity of submicrometer silica spheres via surface modification for nanocomposite applications. Langmuir 2007, 23, 7799-7803. [CrossRef] [PubMed]

11. Manoudis, P.; Karapanagiotis, I.; Tsakalof, A.; Zuburtikudis, I.; Panayiotou, C. Superhydrophobic composite films produced on various substrates. Langmuir 2008, 24, 11225-11232. [CrossRef] [PubMed]

12. Kulkarni, S.A.; Ogale, S.B.; Vijayamohanan, K.P. Tuning the hydrophobic properties of silica particles by surface silanization using mixed self-assembled monolayers. J. Colloid Interface Sci. 2008, 318, 372-379. [CrossRef] [PubMed]

13. Xiu, Y.; Zhu, L.; Hess, D.W.; Wong, C.P. Biomimetic Creation of Hierarchical Surface Structures by Combining Colloidal Self-Assembly and Au Sputter Deposition. Langmuir 2006, 22, 9676-9681. [CrossRef] [PubMed]

14. Yilgor, I.; Bilgin, S.; Isik, M.; Yilgor, E. Tunable Wetting of Polymer Surfaces. Langmuir 2012, 28, 14808-14814. [CrossRef] [PubMed]

15. Yang, T.; Tian, H.; Chen, Y. Preparation of Superhy-drophobic Silica Films with Honeycomb-Like Structure by Emulsion Method. J. Sol-Gel Sci. Technol. 2009, 49, 243-246. [CrossRef]

16. Shang, Q.Q.; Gao, L.J.; Liu, H.; Xiao, G.M. Fabrication of Superhydrophobic Silica Film by Removing Polystyrene Spheres. J. Sol-Gel Sci. Technol. 2011, 59, 334-337. [CrossRef]

17. Xu, D.; Wang, M.; Ge, X.; Lam, M.H.W.; Ge, X. Fabrication of raspberry $\mathrm{SiO}_{2}$ / polystyrene particles and superhydrophobic particulate film with high adhesive force. J. Mater. Chem. 2012, 22, 5784-5791. [CrossRef]

18. Petcu, C.; Nistor, C.L.; Purcar, V.; Cinteza, L.O.; Spataru, C.I.; Ghiurea, M.; Ianchis, R.; Anastasescu, M.; Stoica, M. Facile preparation in two steps of highly hydrophobic coatings onpolypropylene surface. Appl. Surf. Sci. 2015, 347, 359-367. [CrossRef]

19. Purcar, V.; Cinteza, O.; Ghiurea, M.; Balan, A.; Caprarescu, S.; Donescu, D. Influence of the hydrophobic characteristic of organo-modified precursor on the wettability of silica film. Bull. Mater. Sci. 2014, 37, 107-115. [CrossRef]

20. Purcar, V.; Cinteza, O.; Donescu, D.; Bala, D.; Ghiurea, M.; Petcu, C.; Caprarescu, S. Surface modification of silica particles assisted by $\mathrm{CO}_{2}$. J. Supercrit. Fluids 2014, 87, 34-39. [CrossRef]

21. Tsai, H.J.; Lee, Y.L. Facile method to fabricate raspberry-like particulate films for superhydrophobic surfaces. Langmuir 2007, 23, 12687-12692. [CrossRef] [PubMed] 
22. Han, J.T.; Kim, S.; Karim, A. UVO-Tunable Superhydrophobic to Superhydrophilic Wetting Transition on Biomimetic Nanostructured Surfaces. Langmuir 2007, 23, 2608-2614. [CrossRef] [PubMed]

23. Fadeev, A.Y.; McCarthy, T.J. Self-assembly is not the only reaction possible between alkyltrichlorosilanes and surfaces: Monomolecular and oligomeric covalently attached layers of dichloro- and trichloroalkylsilanes on silicon. Langmuir 2000, 16, 7268-7274. [CrossRef]

24. Pham, K.N.; Fullston, D.; Sagoe-Crentsil, K. Surface modification for stability of nano-sized silica colloids. J. Colloid Interface Sci. 2007, 315, 123-127. [CrossRef] [PubMed]

25. Herrera, N.N.; Letoffe, J.M.; Putaux, J.L.; David, L.; Bourgeat-Lami, E. Aqueous dispersions of silane-functionalized laponite clay platelets. A first step toward the elaboration of water-based polymer/clay nanocomposites. Langmuir 2004, 20, 1564-1571.

26. Durdureanu-Angheluta, A.; Ardeleanu, R.; Pinteala, M.; Harabagiu, V.; Chiriac, H.; Simionescu, B.C. Silane covered magnetite particles, preparation and characterization. Dig. J. Nanomater. Biostruct. 2008, 3, $33-40$.

27. Daniel, L.M.; Frost, R.L.; Zhu, H.Y. Edge-Modification of Laponite with Dimethyl-octylmethoxysilane. J. Colloid. Interface Sci. 2008, 321, 302-309. [CrossRef] [PubMed]

28. Zeid, A.A. A Review: Fundamental Aspects of Silicate Mesoporous Materials. Materials 2012, 5, $2874-2902$.

29. Ianchis, R.; Donescu, D.; Petcu, C.; Ghiurea, M.; Anghel, D.F.; Stanga, S.; Marcu, A. Surfactant-free emulsion polymerization of styrene in the presence of silylated montmorillonite. Appl. Clay Sci. 2009, 45, 164-170. [CrossRef]

30. Brambilla, R.; Pires, G.P.; Joãa dos Santos, H.Z.; Lacerda Miranda, M.S.; Chornik, B. Octadecylsilane-modified silicas prepared by grafting and sol-gel methods. J. Electron. Spectrosc. 2007, 156-158, 413-420. [CrossRef]

31. Petcu, C.; Purcar, V.; Ianchis, R.; Spataru, C.I.; Ghiurea, M.; Nicolae, C.A.; Stroescu, H.; Atanase, L.I.; Frone, A.N.; Trica, B.; et al. Synthesis and characterization of polymer-silica hybrid latexes and sol-gel-derived films. Appl. Surf. Sci. 2016, 389, 666-672. [CrossRef]

32. Jeon, B.J.; Hah, H.J.; Koo, S.M.; Byung, J.J.; Hoe, J.H.; Sang, M.K. Surface modification of silica particles with organoalkoxysilanes through two-step (acid-base) process in aqueous solution. J. Ceram. Process. Res. 2002, 3, 216-221.

33. Ianchis, R.; Rosca, I.D.; Ghiurea, M.; Spataru, C.I.; Nicolae, C.A.; Gabor, R.; Raditoiu, V.; Preda, S.; Fierascu, R.C.; Donescu, D. Synthesis and properties of new epoxy-organolayered silicate nanocomposites. Appl. Clay Sci. 2015, 103, 28-33. [CrossRef]

34. Raditoiu, V.; Raditoiu, A.; Wagner, L.E.; Raduly, M.F.; Amăriuţei, V.; Nicolae, C.A.; Fierascu, R.C. Synthesis, characterization and photoisomerization behavior of some organic modified silica-Azo dye hybrid films. Optoelectron. Adv. Mater. Rapid Commun. 2011, 5, 363-369. 